\title{
Patterns of tillering and grain production of winter wheat at a wide range of plant densities
}

\section{A. Darwinkel}

Research Station for Arable Farming and Field Production of Vegetables, Edelhertweg 1, Lelystad, the Netherlands

Accepted: 1 June 1978

Key words: winter wheat, plant density, shoot age, grain yield, yield components, tiller survival, spikelet number, harvest index

\section{Summary}

The effect of plant density on the growth and productivity of the various ear-bearing shoots of winter wheat was studied in detail to obtain information on the pattern of grain production of crops grown under field conditions.

Strong compensation effects were measured: a 160 -fold increase in plant density ( 5 to 800 plants $/ \mathrm{m}^{2}$ ) finally resulted in a 3 -fold increase in grain yield (282 to $\left.850 \mathrm{~g} \mathrm{DM} / \mathrm{m}^{2}\right)$. Maximum grain yield was achieved at 100 plants per $\mathrm{m}^{2}$, which corresponded to 430 ears $/ \mathrm{m}^{2}$ and to about 19000 grains per $\mathrm{m}^{2}$. At higher plant densities more ears and more grains were produced, but grain yield remained constant. Tillering per plant was largely favoured by low plant densities, because these allowed tiller formation to continue for a longer period and a greater proportion of tillers produced ears. Per unit area, however, at higher plant densities more tillers were formed and, despite a higher mortality, more ears were produced.

The productivity of individual ears, from main shoots as well as from tillers, decreased with increasing plant density and with later emergence of shoots. In the range from 5 to 800 plants $/ \mathrm{m}^{2}$ grain yield per ear decreased from 2.40 to $1.14 \mathrm{~g}$ DM. At 800 plants $/ \mathrm{m}^{2}$ nearly alle ears originated from main shoots, but with decreasing plant density tillers contributed increasingly to the number of ears. At 5 plants $/ \mathrm{m}^{2}, 23$ ears were found per plant and grain yield per ear ranged from 4.20 (main shoot) to $1.86 \mathrm{~g} \mathrm{DM}$ (late-formed shoots). Grain number per ear was reduced at higher densities and on younger shoots, because there were fewer fertile spikelets and fewer grains in these spikelets. At the low density of 5 plants $/ \mathrm{m}^{2}$, plants developed solitarily and grain yield per ear was determined by the number of grains per ear as well as by grain weight. Above 400 ears per $\mathrm{m}^{2}$, in this experiment reached at 100 plants $/ \mathrm{m}^{2}$ and more, grain yield per ear depended solely on grain number, because the weights of grains of the various shoots were similar.

The harvest index showed a maximum of about $44 \%$ at a moderate plant densi- 
ty; at this density nearly maximal grain yield was achieved. At low plant densities the harvest index decreased from $45 \%$ in main shoots to about $36 \%$ in late-formed shoots. However, no differences in harvest index existed between the various earbearing shoots if the number of ears exceeded 400 per $\mathrm{m}^{2}$.

\section{Introduction}

Grain yield in cereals depends on three yield components: number of ears per unit area, number of grains per ear and grain weight. A strong mutual compensation is usually found between these components. However, a limitation of one component cannot be completely compensated for by the others. So, for maximal grain yields an undisturbed functioning of the crop is necessary during all stages of growth.

Grain weight predominantly depends on how much the plant assimilates during the stage of grain-filling, and this is closely related to the area of long-lived green leaves, usually called LAD (Spiertz et al., 1971; Thorne, 1974). The favourable results of effective disease control on grain yields are largely based on a higher LAD.

Grain number is considered to be a limiting factor for maximal grain yields (Fisher, 1975; Thorne et al., 1968). In field experiments, Fisher et al. (1976), Puckridge \& Donald (1967) and Willey \& Holliday (1971) found that the increase in grain yield was correlated with increasing grain numbers, but in their experiments grain numbers did not exceed 20000 per $\mathrm{m}^{2}$. It is likely that at higher grain numbers this relationship will become asymptotic. Very high numbers of grains can only be achieved in dense crops, in which radiant energy for grain-filling will be limited and therefore grain weight will decrease. Moreover, at high densities there is less reserve carbohydrate in the ear-bearing shoot before anthesis, whereas crop respiration is higher (Fisher et al., 1977), which again will restrict grain-filling.

Fisher et al. (1977) found that up to a level of 30000 grains per $\mathrm{m}^{2}$, grain yields increased as grain numbers increased, although grain weight gradually decreased. These high grain numbers were due to very high ear densities, which were achieved in experiments by crowding well-developed plants before anthesis. However, such methods are not feasible in field-grown crops.

In individual plants of winter wheat (Darwinkel et al., 1977), spring wheat (Power \& Alessi, 1978) and barley (Gallagher et al., 1976; Thorne, 1962) the yield of the main shoot clearly surpassed that of the tillers. This high yield of main shoots vis-àvis tillers led to a wheat with one culm being chosen as crop ideotype, as described by Donald (1968). But in dense crop situations, the size of the ears of the main shoots depends largely upon the total number of ears. Moreover, at lower plant densities, early-formed tillers are very productive (Darwinkel et al., 1977). In regions with severe winters many plants may be killed by frost. Compensation is mainly achieved by extensive tillering of the surviving plants. In this way wheats with few culms may have greater agronomic value (Atsmon \& Jacobs, 1977).

Because of the higher grain yields of main shoots, the advantages of tillers for grain production remain debatable. Therefore, in an experiment the role of tillers 
was studied at different plant densities. The development and productivity of main shoots and sequential tillers were analysed to ascertain their pattern of grain production.

\section{Materials and methods}

In a field experiment winter wheat (cv. Lely) was sown by hand in small plots well over $1 \mathrm{~m}^{2}$ on 19 October 1976 on a fertile, clayey Flevopolder soil (pH 7.4). The size of the seeds ranged from 2.75 to $3.25 \mathrm{~mm}$; they were placed $20-30 \mathrm{~mm}$ deep on a square grid. Open places were filled up later. The following seven plant densities were obtained: $5,25,50,100,200,400$ and 800 plants $/ \mathrm{m}^{2}$. The scheme was a completely randomized design with four replicates. At harvest, $0.2 \mathrm{~m}^{2}$ of each plot was taken for analysis. To enable a clear comparison to be made between the widely different plant densities, undesirable interactions were obviated as much as possible by preventing damage from mice and birds, controlling disease by frequent applications of fungicides, preventing lodging by using wire-netting, and by supplying adequat nutrients to avoid mineral deficiency. These measures lowered the incoming radiation energy at crop level by about $10 \%$.

During winter and spring the order in which the tillers were formed was established by marking the shoots that were $20-40 \mathrm{~mm}$ long with plastic rings of different colours. The shoots were marked on 10 November (main shoots $=\mathrm{Ms}$ ), 18 February (early tillers = T1), 7 March (T2), 24 March (T3), 4 April (T4), 15 April (T5)

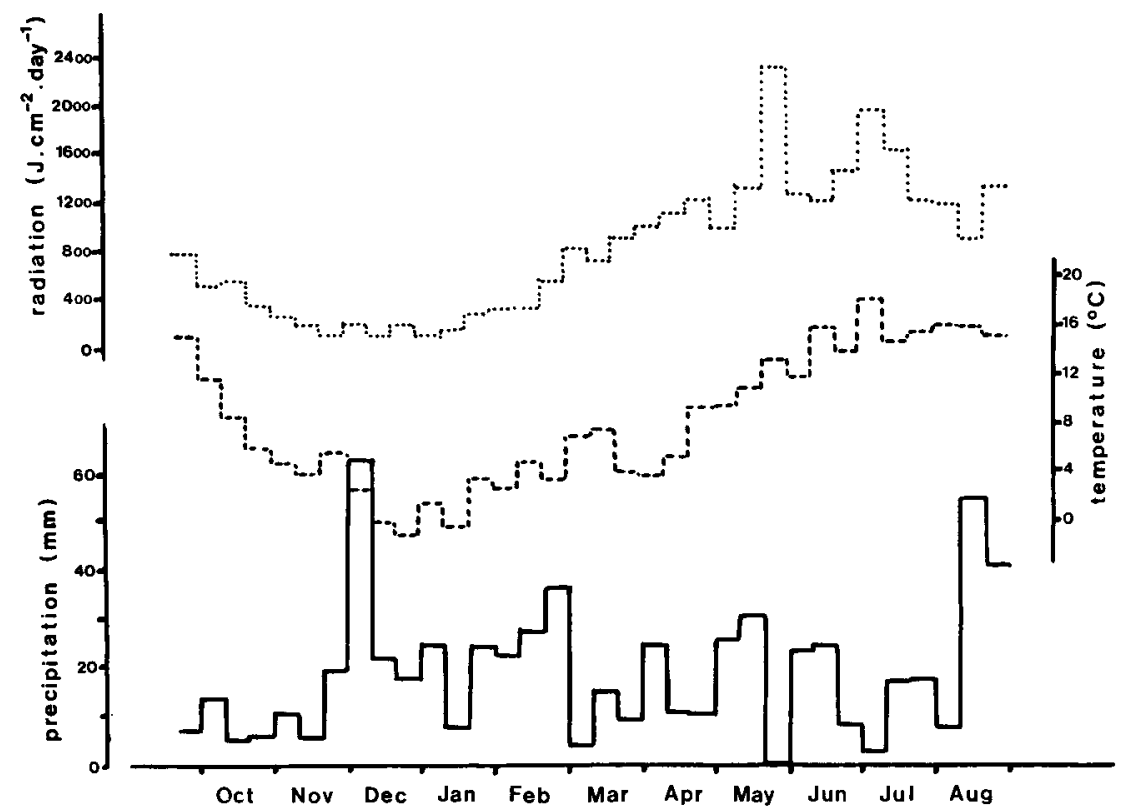

Fig. 1. Weather conditions during the growing period (October 1976 - August 1977). Precipitation $(-)$, mean daily temperature $(-.-)$ and mean daily radiation (....) per decade. 
and 25 April (T6); tillers formed after 25 April (T7) were not marked. This enabled the shoots to be classified according to age and their development to be recorded easily. The first markings were made when approximately one tiller per plant had emerged at all densities. On later dates the age classes often consisted of more than one tiller, especially at low plant densities. At harvest, the weight of grains, straw and chaff, the number of ears, fertile and empty spikelets and grains per ear were determined. For the determination of dry matter yields, plant material was dried at $105^{\circ} \mathrm{C}$ for at least 16 hours.

The spikelets were counted at maturation. Fertile spikelets could easily be identified, but empty, apical spikelets decreased sharply in size, which impeded counting. Thus the total number of spikelets counted might not be exactly the number of spikelets initiated.

Temperature, water supply and light intensity are important factors in crop growth. Weather conditions during the growth of winter wheat in this experiment are presented in Fig. 1.

\section{Results}

Table 1 summarizes the effect of plant density on some crop characteristics. The number of tillers and the number of ears per unit area increased with increasing plant density. However, the 160 -fold increase in plant density led to a 12 -fold increase in tiller number, to a 7-fold increase in ear number and to a 3-fold increase in grain yield. So, a considerable compensation for ear density occurred at low seed rates, due to abundant tillering and the higher fertility of the tillers.

Grain yield approached a maximum at about 100 plants $/ \mathrm{m}^{2}$, yielding 430 ears/ $\mathrm{m}^{2}$, whereas the above-ground dry matter yield increased over the whole range of plant densities. The harvest index, indicating the proportion of grain yield to total above-ground yield, therefore first increased to a maximum, but then declined as plant densities increased. The response of grain weight to plant density was similar. With increasing plant densities, grain weight reached a maximum at 50 plants $/ \mathrm{m}^{2}$, but decreased with higher densities.

Table 1. Yield and some crop characteristics at different plant densities.

\begin{tabular}{rclllll}
\hline $\begin{array}{l}\text { Plants } \\
\text { per } \mathrm{m}^{2}\end{array}$ & $\begin{array}{l}\text { Tillers } \\
\text { formed } \\
\text { per } \mathrm{m}^{2}\end{array}$ & $\begin{array}{l}\text { Ears } \\
\text { per } \mathrm{m}^{2}\end{array}$ & $\begin{array}{l}\text { Grain } \\
\text { yield } \\
\left(\mathrm{g} \mathrm{DM} / \mathrm{m}^{2}\right)\end{array}$ & $\begin{array}{l}\text { Total } \\
\text { yield } \\
\left(\mathrm{g} \mathrm{DM} / \mathrm{m}^{2}\right)\end{array}$ & $\begin{array}{l}\text { Grain } \\
\text { weight } \\
(\mathrm{mg})\end{array}$ & $\begin{array}{l}\text { Harvest } \\
\text { index }\end{array}$ \\
5 & 145 & 118 & 282 & 707 & 40.3 & 39.9 \\
25 & 492 & 272 & 644 & 1531 & 41.7 & 42.1 \\
50 & 691 & 322 & 720 & 1647 & 44.6 & 43.7 \\
100 & 977 & 430 & 843 & 1968 & 44.1 & 42.8 \\
200 & 929 & 490 & 834 & 2024 & 42.3 & 41.2 \\
400 & 1232 & 582 & 848 & 2181 & 41.0 & 38.9 \\
800 & 1780 & 777 & 890 & 2376 & 39.0 & 37.5 \\
\hline
\end{tabular}




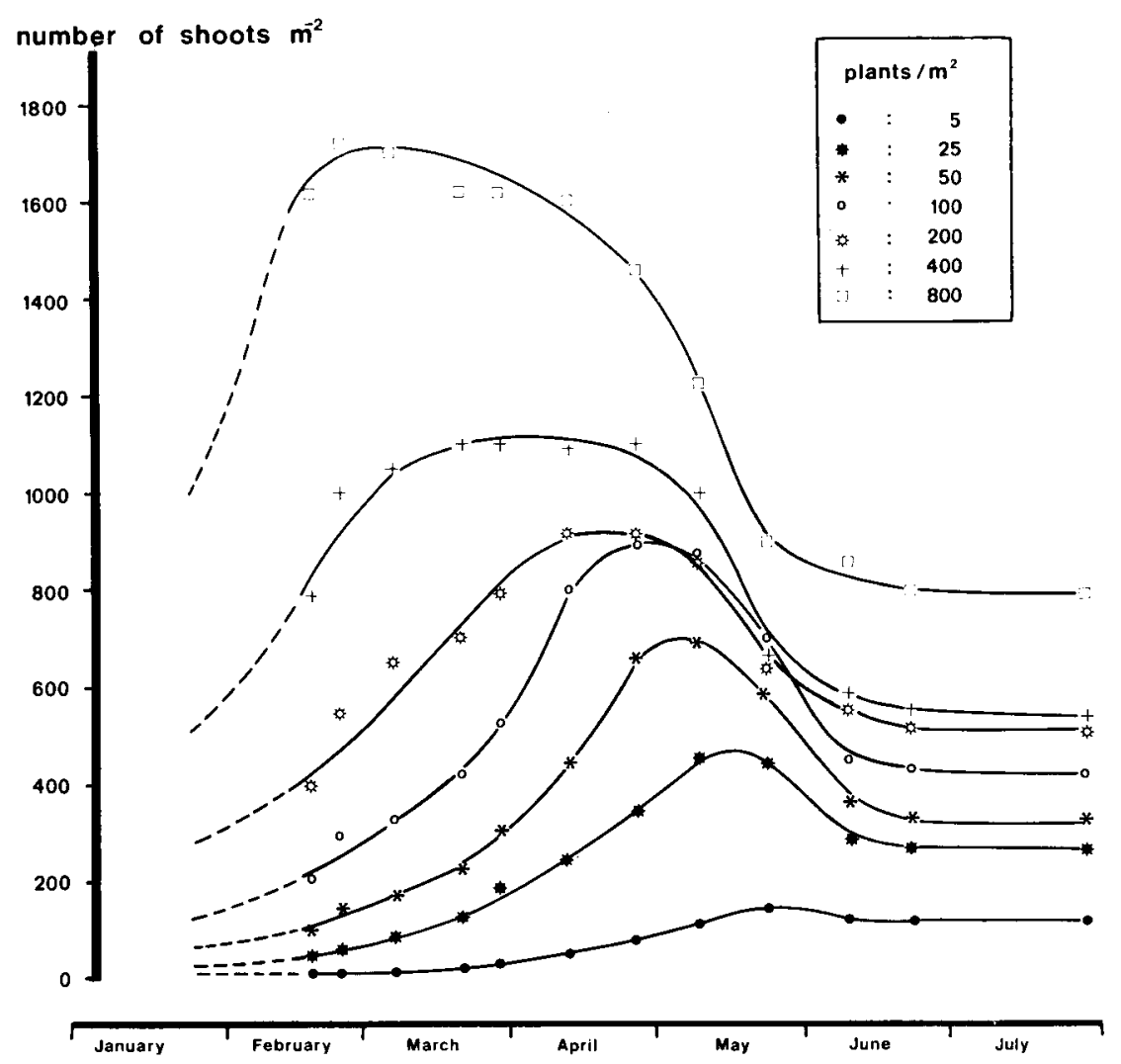

Fig. 2. Course of the number of shoots at different plant densities during the growing period.

\section{Pattern of tillering}

The late autumn was rather mild, and growth proceeded favourably. In mid-December tillering started at all plant densities. From this date onwards the numbers of living shoots (i.e. main shoots plus tillers) were counted at intervals. This enabled the course of the number of shoots during the growing period to be ascertained (Fig. 2). At first, the number of shoots increased rapidly to a maximum, and then gradually declined.

At greater plant densities, more shoots were produced per $\mathrm{m}^{2}$. The maximum number of shoots was achieved earlier when plant density was higher. At 800 plants $/ \mathrm{m}^{2}$ this maximum was recorded at the beginning of March, but at 5 plants $/ \mathrm{m}^{2}$ it was not recorded until the end of May. So, with increasing plant density the maximum number of shoots produced was higher and was attained earlier in the season. Senescence of shoots started earlier at higher densities, but stopped for all densities shortly before anthesis in mid-June. 


\section{Tiller survival and ear formation}

As is shown in Table 1, only a proportion of the tillers produced reached the reproductive stage. This proportion increased as plant density decreased. At 5 plants per $\mathrm{m}^{2}$ about $80 \%$ of the shoots produced ears, whereas at higher densities this percentage was reduced to $45 \%$. Usually, the earlier the date of tiller formation, the better was the size of the tillers at jointing stage. At all plant densities, the survival of tillers was clearly better the earlier the tillers had been established (Fig. 3). Thus, all main shoots produced ears, except at $800 \mathrm{plant} / \mathrm{m}^{2}$ where $6 \%$ of the main shoots died.

The transition of tillers of different age into the reproductive stage depended largely on plant density. In plants at the very low density of 5 per $\mathrm{m}^{2}$, the 11 earliest formed tillers were reproductive. Tillers that emerged at a very late date only partially underwent reproductive development. This poor ear production from lateformed tillers was found at all plant densities. Yet at rather low densities fairly late tillers such as T4 and T5 came into ear, but reproductive development of these tiller classes decreased as plant densities increased. At 400 plants $/ \mathrm{m}^{2}, 40 \%$ of the first tillers (T1) and only $8 \%$ of the second tillers (T2) survived. At 800 plants $/ \mathrm{m}^{2}$ almost all the tillers died and so most of the ears originated from main shoots. At this very dense plant population almost all the plants consisted of one ear, as can be seen in Fig. 4. With lower plant densities the number of ears per plant increased consistently to 23 ears at 5 plants $/ \mathrm{m}^{2}$. Thus, the proportion of ears originating from main shoots decreased gradually as plant density decreased, and so the contribution of tillers to final grain yield became increasingly important. In plants sown at moderate densities of 100 to 200 per $\mathrm{m}^{2}$ the first 3 tillers formed contributed largely to the final number of $400-500$ ears per $\mathrm{m}^{2}$, which is considered desirable for achieving reliable, high grain yields in the Netherlands.

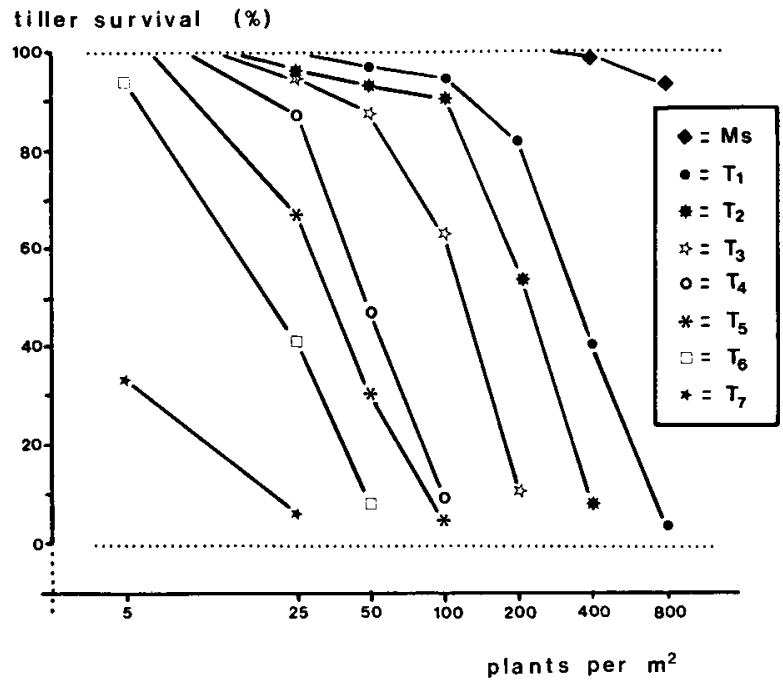

Fig. 3. Survival of tillers of different age-classes $(\mathrm{Ms}=$ main shoot; $\mathbf{T} 1-\mathbf{T} 7=$ first - seventh class of tillers). 


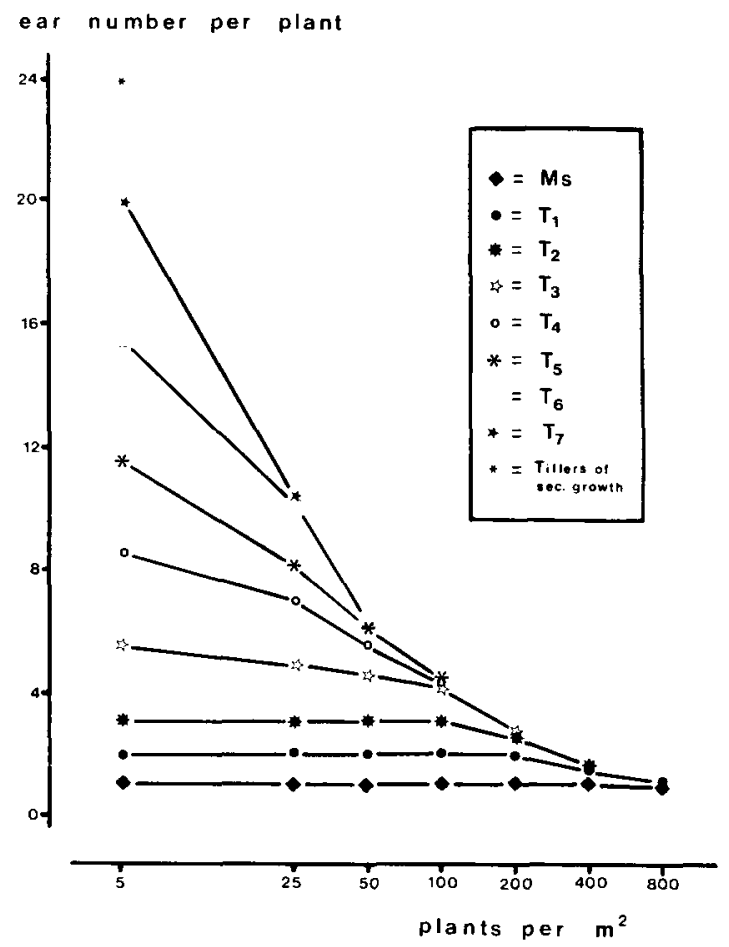

Fig. 4. Mean number of ears per plant. Cumulative representation referring to shoot age.

\section{Spikelet development}

Up to 100 plants per $\mathrm{m}^{2}$ the mean total number of spikelets initiated per ear was fairly constant at about 25 . It decreased with higher densities to just over 21 at 800 plants $/ \mathrm{m}^{2}$ (Fig. 5). The number of fertile spikelets per ear showed an optimum near 50 plants $/ \mathrm{m}^{2}$. A considerable decrease in the number of fertile spikelets was observed at higher densities. On the contrary, the response of the numbers of empty spikelets to plant density was reverse.

The localization of empty spikelets in the ear was markedly influenced by plant density. At 5 plants per $\mathrm{m}^{2}$ each plant had an average of 4.5 empty spikelets at the top and only 1.5 at the base of the ear. With increasing plant density, the number of empty spikelets at the top decreased, but increased at the base. So, at 800 plants/ $\mathrm{m}^{2}$ the situation was completely reversed; on average 5.1 basipetal and 1.1 apical empty spikelets were measured per plant. Clear differences in the number of fertile and empty spikelets occurred between the ears within each plant. In Fig. 6 it can be seen that shoot age had relatively little effect on the total number of spikelets initiated. However, the number of fertile spikelets was markedly higher in shoots that had been established earlier. The reverse was true of empty spikelets: later emergence of shoots caused the number of empty spikelets in the ear to increase basipetally as well as apically. Shoot age was found to affect spikelet number at all plant densities, but at a different level. With increasing densities a decrease of 


\section{A. DARWINKEL}

fertile spikelets and an increase of empty spikelets were observed for all ear-bearing shoots.

\section{Number of grains}

The number of grains per ear is determined before anthesis. It depends largely on the initiation, differentiation and further development of spikelets. The number of well-grown spikelets and their fertility determine the number of grains produced. Thus the number of grains per ear can vary widely. Fig. 5 shows a considerable decrease in grain number per ear at higher plant densities. As plant density increased from 5 to 800 plants $/ \mathrm{m}^{2}$, grain number per ear was halved. As well as the reduction in fertile spikelets mentioned earlier, the number of grains per spikelet also diminished as plant density increased.

The response of ear development to shoot age was reflected in the number of grains per fertile spikelet and in the number of grains per ear, and finally in grain yield per ear (Fig. 7). Plant density and shoot age influenced the number of grains per fertile spikelet. Later-emerged shoots produced ears that contained somewhat fewer grains per fertile spikelet. Moreover, there were fewer fertile spikelets (Fig. 6), and so grain number per ear was considerably smaller the later the ear-bearing shoot emerged. This was very obvious at low plant densities, in which the plants consisted of a large number of shoots, clearly differing in age. However, the decrease in grain

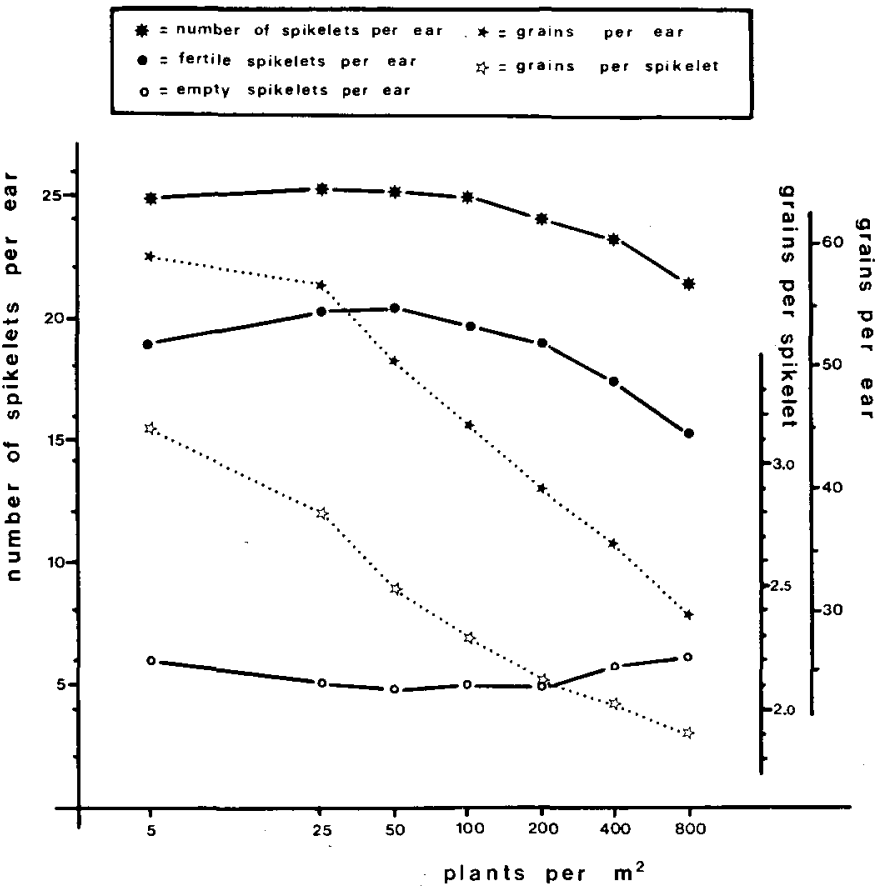

Fig. 5. Number of grains and spikelets per ear and the number of grains per fertile spikelet. 


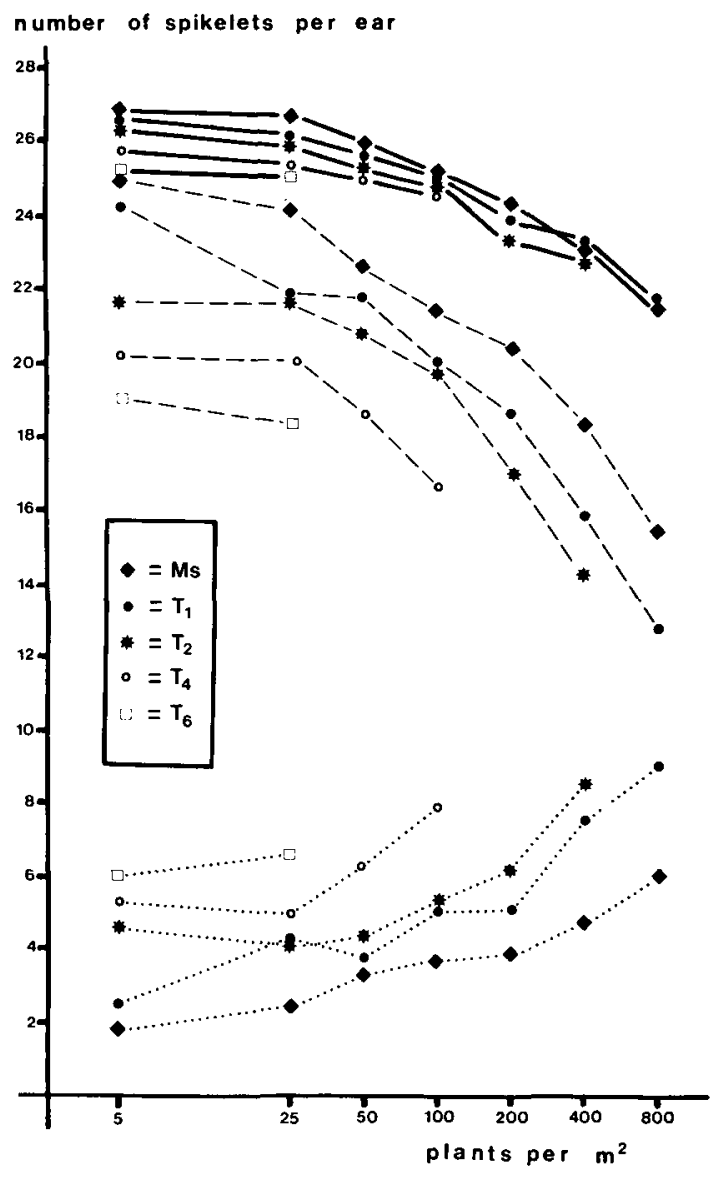

Fig. 6. Total number of spikelets $(-)$, fertile spikelets $(---)$ and empty spikelets (....) per ear as affected by shoot age.

number per ear with higher plant densities was such that main shoots had fewer grains than ear-bearing tillers at lower plant densities.

\section{Weight of grains}

The response of grain weight to plant density was shown in Table 1 . Shoot age influenced grain weight only at the low densities of 5 and 25 plants $/ \mathrm{m}^{2}$ : shoots that emerged earlier had heavier grains. At higher plant densities there was no relationship between shoot age and grain weight.

Grain yield per ear was considerably influenced by plant density and shoot age (Fig. 7). Grain yield per ear decreased as plant density increased and as the earbearing shoot emerged later. However, at low plant densities the grain yield per ear was affected more markedly than at high densities.

\section{Harvest index}

The proportion of grain yield to above-ground yield (harvest index) showed a 


\section{A. DARWINKEL}


Fig. 7. Number of fertile spikelets (a), number of grains (b), weight of grains (c) and grain yield (d) per ear of shoots of different age-classes. 


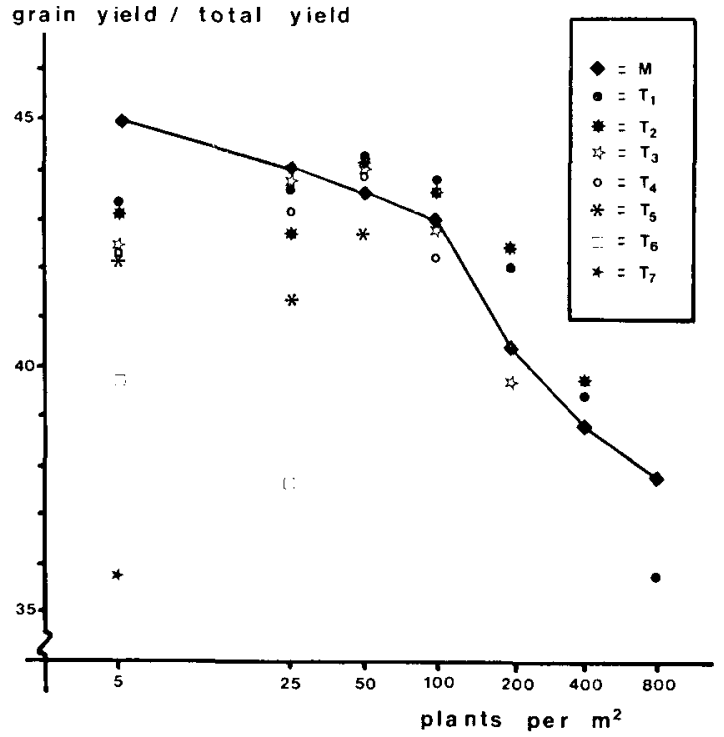

Fig. 8. Distribution of dry matter in aerial plant parts, indicated as harvest index, for shoots of different age-classes.

maximum at a density of 50 plants $/ \mathrm{m}^{2}$ (Table 1 ). The response of dry matter distribution to shoot age at increasing plant density is presented in Fig. 8. The proportion of the dry matter found in grains from main shoots gradually decreased with higher densities. At low densities ( 5 and 25 plants $\left./ \mathrm{m}^{2}\right)$ dry matter found in grains decreased considerably with later emergence of shoots. At densities of 50 plants $/ \mathrm{m}^{2}$ or more, this effect of shoot age was absent.

\section{Discussion}

In many crops the effects of plant density on yield are generally attributed to interplant and intraplant competition for light, water and nutrients, and to the incidence of diseases. When plants that may have a prolonged solitary development (e.g. tillering cereals) are grown as a crop, both kinds of competition will greatly influence growth and productivity.

Tillering, ear formation and productivity of an ear-bearing shoot will be determined by its location within the stand and by growing conditions. Competition for light, the supply of nutrients and water, and the rate of plant development determine all the physiological processes from initiation up to and inclusive grain-filling. Within the plant, competition for assimilates between stems and ear may largely influence ear development (Gallagher et al., 1976). The size of the ear mostly depends upon the conditions prevailing during the growth stages, at which initiation, differentiation and fertilization of spikelets take place. Lupton \& Kirby (1968) suggest that there is great scope for crop improvement by altering the relative lengths of successive phases in the growth cycle of cereals. Prolonging the period during which the ear develops might cause an increase in the number of spikelets formed, 
or in the number of flower primordia per spikelet. Rawson (1970) points out that an increase in spikelet number per ear is always associated with a longer duration of ear development. The rate of plant development is determined by the length of the successive growth stages and depends upon cultivar characteristics, photoperiod (Allison \& Daynard, 1976), light intensity and temperature (Friend, 1965). Moreover, in cultivars with a pronounced response to vernalization, the length of the period to floral initiation was of prime importance for establishing the potential spikelet sites (Rawson, 1970).

In the experiment described here, competition for light was most important, because the supply of water and nutrients was sufficient and damage due to lodging, diseases and pests was prevented. Therefore the supply of carbohydrates was the most influential factor for all physiological processes from tiller formation to grainfilling. But, despite a sufficient supply of nutrients, it is still possible to have an imbalance in the distribution of nutrients within the plant, and this can also affect intraplant competition.

With increasing plant densities, interplant competition was more severe, began earlier and limited plant growth, whereas at lower densities more tillers were produced per plant, resulting in greater intraplant competition. At 800 plants $/ \mathrm{m}^{2}$, only interplant competition occurred, and only a few tillers grew into ears. At 5 plants/ $\mathbf{m}^{2}$, plants developed solitarily and many tillers produced ears, resulting in severe intraplant competition. At intermediate densities both types of competition occurred during the growing period. Because interplant competition began earlier with higher plant densities, the effect of plant density on numbers of spikelets initiated, numbers of fertile spikelets and numbers of grains per spikelet and per ear was intensified (Fig. 5).

The time and rate of tillering depended largely upon plant density. All the first tillers emerged at approximately the same time regardless of plant density, but the higher the plant density, the fewer subsequent tillers were formed. Tillering also ceased earlier at higher plant density (Fig. 2), as was also found by Puckridge \& Donald (1967). With increasing densities the space per plant diminished and so interplant competition set in earlier. At low plant densities no interplant competition occurred, and abundant and prolonged tillering took place, so that a very high number of shoots per plant was established (Fig. 3).

At high densities early interplant competition not only reduced shoot number but also shoot size. Only well-developed shoots produced ears. The earlier the shoots emerged, the better was their growth and reproductive behaviour. At 800 plants $/ \mathrm{m}^{2}$, only a few tillers became reproductive. With decreasing densities more tillers produced ears. At 5 plants $/ \mathrm{m}^{2}$, late-formed tillers also had good conditions for growth and most were reproductive. At all densities the mortality of tillers increased with later tiller formation. This effect of shoot age on tiller survival is comparable with the findings of Thorne (1962) with barley and of Power \& Alessi (1978) with spring wheat.

As plant density decreased, tillering continued longer and more tillers were established. Late-formed tillers are located at the base of a well-developed plant, a situation where light interception is restricted, resulting in low production of carbo- 
hydrates. Furthermore, apical dominance discriminates against the growth of these tillers. Thus the survival and ear growth of late tillers are poor. In addition, lateformed tillers develop more rapidly, and this restricts ear size. So, the later the tiller emerges, the worse the chances will be for the growing ear.

Within a plant there is considerable variation in the number of spikelets and grains per ear, as is shown in Fig. 6 and 7. This variation is closely related to the rate at which the ear develops from initiation to anthesis.

The relation between total number of spikelets and shoot age was fairly small at all plant densities. At 5 plants $/ \mathrm{m}^{2}$, the total number of spikelets per ear gradually decreased from 26.8 (Ms) to 24.7 (T7). This suggests that spikelet initiation is only slightly influenced by shoot age, but it must be remembered that only the spikelets in ear-bearing shoots were counted, and these shoots undoubtedly had rather favourable conditions for growth.

At high plant densities, competition for light greatly affected ear development from early growth stages onwards (Puckridge, 1968). This effect can also be seen in the initiation and fertility of spikelets in main shoots (Fig. 6). At 5 plants $/ \mathrm{m}^{2}$ 26.8 spikelets were initiated in main shoots, of which 25.0 produced grains, whereas at 800 plants $/ \mathrm{m}^{2}$ only 15.4 of the 21.4 spikelets initiated contained grains at harvest. Above 50 plants $/ \mathrm{m}^{2}$, the number of fertile spikelets decreased with higher plant densities (Fig. 5). At lower densities, however, the number of fertile spikelets was hardly affected, because the plants consisted of an increasing number of ears, originated from later-formed shoots with fewer fertile spikelets.

Spikelet development was greatly influenced by shoot age. At each plant density, the number of spikelets initiated per tiller decreased with later emergence of tillers (Fig. 6). The higher interplant and intraplant competition during the growing period hampered the enlargement of spikelets initiated in later-formed tillers. This phenomenon was apparent from a marked decrease in number of fertile spikelets at the expense of an increase of empty spikelets. At 5 plants $/ \mathrm{m}^{2}$ shoots of secondary growth contained on average only 12.5 fertile and as much as 9.9 empty spikelets. Gallagher et al. (1976) also found that main shoots in barley initiated more spikelets per ear and these had a higher fertility than those produced by tillers.

It is noteworthy that at low plant densities most of the empty spikelets were situated apically. With increasing plant densities fewer empty spikelets were found at the top of the ear, but more were found at the base. Kirby (1974) gave a clear picture of the patterns of initiation, differentiation and fertilization of spikelets within a wheat ear. However, the relation between localization of empty spikelets and plant density is still not fully understood.

The relatively favourable growing conditions for main shoots and early formed ear-bearing tillers are also expressed in a higher number of grains per spikelet and per ear (Fig. 7). Later-formed shoots had fewer grains per ear. This effect remained as plant density increased, but the intensification of interplant competition resulted in a reduction in the level of grain number. There were fewer fertile spikelets in later-formed shoots (Fig. 6), but also fewer grains per fertile spikelet. In these lateformed shoots, the supply of carbohydrates for the process of seed-setting lagged behind that of main shoots, especially at the low density of 5 plants $/ \mathrm{m}^{2}$ (Fig. 7). 
The number of grains per ear decreased, the younger the shoot and the higher the plant density. The obvious effects of shoot age and plant density are traceable to their combined effect on the number of fertile spikelets and the number of grains per fertile spikelet (Fig. 7). Shortly after anthesis a wide variation in ear size was observed. In younger shoots and in shoots from plants grown at higher densities ear size was smaller. This was undoubtedly caused by insufficient assimilation.

Grain weight depended largely upon plant density. At higher densities lower grain weights were found, because increased interplant competition restricted the supply of carbohydrates required for grain-filling. By contrast, at both the lowest densities, plants grew up more or less solitarily and intraplant competition resulted in a clear decrease in grain weight in ears from younger shoots.

In young shoots the carbohydrate supply is rather limited, but also fewer grains need to be filled. At all densities above 50 plants $/ \mathrm{m}^{2}$, corresponding to more than 322 ears $/ \mathrm{m}^{2}$, no clear differences in weight of grains between shoots of different age were found. Thus it can be inferred that at such densities the supply of carbohydrates to each grain was similar for each shoot.

In densities up to 100 plants $/ \mathrm{m}^{2}$ grain yield increased. At higher densities it remained constant (Table 1). Fig. 9 shows that maximum grain yield was already achieved at approximately 400 ears $/ \mathrm{m}^{2}$. This corresponds to about 19000 grains/ $\mathrm{m}^{2}$. A higher grain number, which could be obtained by increasing the density and thus the ear number, did not increase grain yield, because grain weight decreased correspondingly. This suggests that maximum grain yield can be achieved in different stands. At a density of 100 plants $/ \mathrm{m}^{2}, 23 \%$ of the total number of ears were borne on main shoots, but at a density of 800 plants $/ \mathrm{m}^{2}$ this proportion was $96 \%$.

Grain yield per ear decreased with increasing plant density. Both the grain num-

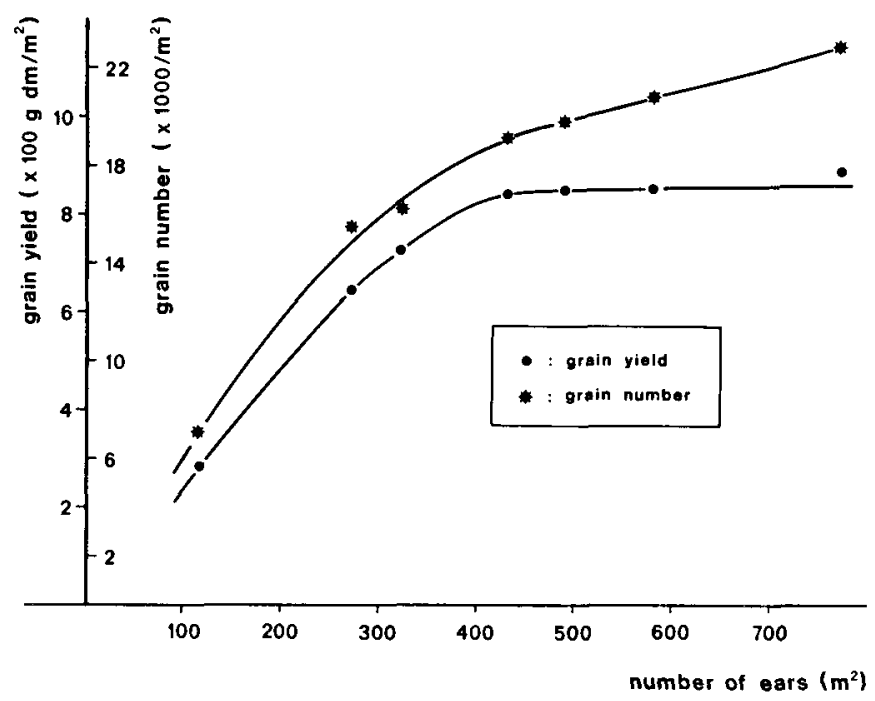

Fig. 9. Mean grain yield and mean grain number at different densities. 
ber and grain weight decreased. In the plants sown at a density of 5 plants $/ \mathrm{m}^{2}$ the lower grain weight of late-formed shoots lagged so far behind that of plants sown at 25 per $\mathrm{m}^{2}$ that the higher grain number did not result in higher grain yield per ear.

At all plant densities, grain yield per ear depended on shoot age. Later-formed shoots had a lower grain number per ear because they had fewer fertile spikelets (Fig. 6) and fewer grains per spikelet (Fig. 7). At densities of 5 and 25 plants $/ \mathrm{m}^{2}$, grain weight was also less. At all densities above $25 \mathrm{plants} / \mathrm{m}^{2}$, grain weight was not affected by shoot age, and thus the grain yield of each ear depended almost entirely on the number of grains. In spring wheat Power \& Alessi (1978) found a small decrease in grain yield in ears from younger shoots; in their experiments grain number remained fairly constant, but grain weight decreased a little.

A harvest index indicating a high proportion of grain yield to total above-ground yield is often mentioned as an important factor of high grain yields. Maintaining total yield, but shortening the straw length resulted in a greater proportion of assimilates entering the grain (Spiertz, 1973). With increasing plant density a lowering of the harvest index is usually observed (Fisher et al., 1976). In this experiment the harvest index decreased in plants sown at densities above 50 plants $/ \mathrm{m}^{2}$. This was because more and longer stems were formed, which gave a higher total yield (Table 1) but did not influence grain yield. At densities below 50 plants $/ \mathrm{m}^{2}$ the low grain yield of the many late-formed shoots depressed the harvest index. The maximum harvest index was found at 50 plants $/ \mathrm{m}^{2}$.

The effect of shoot age on harvest index was pronounced at low plant densities, but disappeared at plant densities which produced at least 322 ears per $\mathrm{m}^{2}$ (Fig. 8). Then, irrespective of plant density, the distribution of assimilates was the same for all ear-bearing shoots. This means, that in crop situations of 350 ears per $\mathrm{m}^{2}$ and more, as are usually found in practice, grain yield is independent of the composition of the ear population.

\section{Acknowledgments}

The author wishes to acknowledge the valuble comments on this manuscript made by Ir L. J. P. Kupers, Ir G. Liefstingh, Ir J. H. J. Spiertz and Prof. Dr Ir G. J. Vervelde. For their assistance in carrying out this experiment the author is much indebted to Mr J. J. Kroon and Mr R. Vroon.

\section{References}

Allison, J. C. S. \& T. B. Daynard, 1976. Effect of photoperiod on development and number of spikelets of a temperate and some low-latitude wheats. Ann. appl. Biol. 83: 93-102.

Atsmon, D. \& E. Jacobs, 1977. A newly bred 'Gigas' form of bread wheat (Triticum eastivum L.): Morphological features and thermo-photoperiodic responses. Crop Sci. 17: 31-35.

Darwinkel, A., B. A. ten Hag \& J. Kuizenga, 1977. Effect of sowing date and seed rate on crop development and grain production of winter wheat. Neth. J. agric. Sci. 25: 83-94.

Donald, C. M., 1968. The breeding of crop ideotypes. Euphytica 17: 385-403.

Fisher, R. A., 1975. Yield potential in a dwarf spring wheat and the effect of shading. Crop Sci. 15: 607-613.

Fisher, R. A., I. Aquilar \& D. R. Laing, 1977. Post-anthesis sink size in a high yielding dwarf 
wheat: Yield response to grain number. Aust. J. agric. Res. 28: 165-175.

Fisher, R. A., I. Aquilar, R. Maurer \& S. Rivas, 1976. Density and row spacing effects on irrigated short wheats at low latitude. J. agric. Sci., Camb. 87: 137-147.

Friend, D. J. C., 1965. Ear length and spikelet number of wheat grown at different temperatures and light intensities. Can. J. Bot. 43: 345-353.

Gallagher, J. N., P. V. Biscoe \& R. K. Scott, 1976. Barley and its environment. IV. Growth and development in relation to yield. J. appl. Ecol. 13: 563-583.

Kirby, E. J. M., 1974. Ear development in spring wheat. J. agric. Sci., Camb. 82: 437-447.

Lupton, F. G. H. \& E. J. M. Kirby, 1968. Applications of physiological analysis to cereal breeding. Rep. Pl. Breed. Inst. Camb. for 1966-67: 5-26.

Power, J. F. \& J. Alessi, 1978. Tiller development and yield of standard and semidwarf spring wheat varieties as affected by nitrogen fertilizer. J. agric. Sci., Camb. 90: 97-108.

Puckridge, D. W., 1968. Competition for light and its effect on leaf and spikelet development of wheat plants. Aust. J. agric. Res. 19: 191-201.

Puckridge, D. W. \& C. M. Donald, 1967. Competition among wheat plants sown at a wide range of densities. Aust. J. agric. Res. 18: 193-211.

Rawson, H. M., 1970. Spikelet number, its control and relation to yield per ear in wheat. Aust. J. biol. Sci. 23: 1-15.

Spiertz, J. H. J., 1973. Effects of successive applications of maneb and benomyl on growth and yield of five wheat varieties of different heights. Neth. J. agric. Sci. 21: 282-296.

Spiertz, J. H. J., B. A. ten Hag \& L. J. P. Kupers, 1971. Relation between green area duration and grain yield in some varieties of spring wheat. Neth. J. agric. Sci. 19: 211-222.

Thorne, G. N., 1962. Survival of tillers and distribution of dry matter between ear and shoot of barley varieties. Ann. Bot. 26: 37-54.

Thorne, G. N., 1974. Physiology of grain yield of wheat and barley. Rep. Rothamsted exp. Stn for 1973 (Part 2) 5-25.

Thorne, G. N., M. A. Ford \& D. J. Watson, 1968. Growth, development, and yield of spring wheat in artificial climates. Ann. Bot. 32: 425-446.

Willey, R. W. \& R. Holliday, 1971. Plant population, shading and thinning studies in wheat. J. agric. Sci., Camb. 77: 453-461. 